\title{
RANTES gene polymorphisms and risk of pediatric asthma: A meta-analysis
}

\author{
YAN-MING LU, LAN-FANG CAO, YA-QIN LI and CHEN LI \\ Department of Pediatrics, Renji Hospital Affiliated to Medical School, \\ Shanghai Jiaotong University, Shanghai 200001, P.R. China
}

Received June 5, 2012; Accepted August 7, 2012

DOI: $10.3892 /$ etm.2012.684

\begin{abstract}
Numerous studies have evaluated the association between regulated upon activation, normal $\mathrm{T}$ cells expressed and secreted (RANTES) gene polymorphisms (-403G/A and $-28 \mathrm{C} / \mathrm{G}$ ) and risk of pediatric asthma. However, the results have been inconsistent. A meta-analysis of the association between RANTES gene polymorphisms and pediatric asthma risk was performed in the current study. A search for published literature was conducted in the Google Scholar, PubMed and the CNKI databases (January 2000 to April 2012) and seven studies were retrieved. The associations between RANTES gene polymorphisms and pediatric asthma risk were estimated by pooled odds ratio (OR) and $95 \%$ confidence interval (CI) using a fixed- or random-effects model. Meta-analysis results revealed no significant association between the $-403 \mathrm{G} / \mathrm{A}$ polymorphism and risk of pediatric asthma. In the subgroup analysis by ethnicity, no association was identified between the $-403 \mathrm{G} / \mathrm{A}$ polymorphism and pediatric asthma risk in Caucasian and Asian populations. In the $-28 \mathrm{C} / \mathrm{G}$ group, the meta-analysis indicated a significant association between the $-28 \mathrm{C} / \mathrm{G}$ polymorphism and pediatric asthma susceptibility among the total population (recessive model: OR, 1.34; $95 \%$ CI, 1.04-1.72). However, when the subgroup analysis was performed by ethnicity, no significant associations were identified in Asians and Europeans. This result suggests that the $-28 \mathrm{C} / \mathrm{G}$ polymorphism may not be associated with pediatric asthma risk, while the observed increase in the risk of pediatric asthma may be due to racial differences. Additional large-scale studies are required to provide conclusive evidence on the effects of RANTES gene polymorphisms on the risk of pediatric asthma.
\end{abstract}

Correspondence to: Dr Lan-Fang Cao, Department of Pediatrics, Renji Hospital Affiliated to Medical School, No. 145 Central Shangdong Road, Shanghai Jiaotong University, Shanghai 200001, P.R. China

E-mail: 2374262033@qq.com

Key words: RANTES, pediatric asthma, meta-analysis, polymorphism

\section{Introduction}

Asthma is a chronic inflammatory disease of the respiratory airways leading to episodes of wheezing, shortness of breath, chest tightness and coughing (1). Approximately 300 million individuals are affected by asthma globally, including 10 million children (2). The pathogenesis of asthma is extremely complex and not fully understood. The major risk factors for the development and persistence of asthma are allergic disease, reduced lung function and viral and bacterial infections (3-5). In addition, variants in over 40 genes have been associated with asthma (6). Parental asthma is a strong predictor of childhood asthma, suggesting a strong genetic basis of pediatric asthma (7).

The regulated upon activation, normal $\mathrm{T}$ cells expressed and secreted (RANTES) protein is one of the most extensively studied chemokines in allergic and infectious diseases (8). RANTES is likely to be significant in airway inflammation, since blocking antibodies to RANTES reportedly inhibit airway inflammation in a murine model of allergic airway disease (8). Two polymorphisms in the RANTES promoter region $(-28 \mathrm{C} / \mathrm{G}$ and $-403 \mathrm{G} / \mathrm{A})$ have been demonstrated to affect the transcription of the RANTES gene and exacerbate asthma severity $(9,10)$. However, the published results have been controversial. To aid the clarification of the inconsistent findings, with the publication of several more recent studies, this meta-analysis of RANTES gene polymorphisms (-403G/A and $-28 \mathrm{C} / \mathrm{G})$ and the risk of pediatric asthma was conducted.

\section{Materials and methods}

Selection of studies. The data were independently gathered in duplicate by two investigators on the basis of a standard protocol (Y.M.L. and L.F.C.). Discrepancies between the investigators were settled by discussion until consensus was reached. Literature databases were searched, including PubMed, Google Scholar and the China National Knowledge Infrastructure (CNKI) databases. The following key words and subject terms were searched: 'RANTES', '-403G/A', '-28C/G', 'pediatric asthma' and 'gene polymorphism'. The reference lists of retrieved reviews and articles were handsearched. The search was without restriction on language and was conducted on human subjects. The literature search was updated on 30 May 2012. 
Table I. Characteristics of the included studies for meta-analysis.

A, -403G/A polymorphism

\begin{tabular}{|c|c|c|c|c|c|c|c|c|c|c|c|}
\hline \multirow[b]{2}{*}{ First author (Refs.) } & \multirow[b]{2}{*}{ Year } & \multirow[b]{2}{*}{ Area } & \multirow[b]{2}{*}{ Ethnicity } & \multirow{2}{*}{$\begin{array}{l}\text { Cases/ } \\
\text { controls }\end{array}$} & \multicolumn{3}{|c|}{ Case genotypes } & \multicolumn{3}{|c|}{ Control genotypes } & \multirow{2}{*}{$\begin{array}{c}\text { HWE } \\
\text { test }\end{array}$} \\
\hline & & & & & GG & GA & $\mathrm{AA}$ & GG & GA & AA & \\
\hline Szalai (11) & 2001 & Hungary & Caucasian & $160 / 303$ & 122 & 32 & 6 & 211 & 84 & 8 & 0.92 \\
\hline Yao (12) & 2003 & China & Asian & $182 / 107$ & 98 & 65 & 19 & 60 & 41 & 6 & 0.77 \\
\hline Liu (13) & 2005 & China & Asian & $32 / 32$ & 17 & 13 & 2 & 16 & 14 & 2 & 0.64 \\
\hline Leung (14) & 2005 & China & Asian & $129 / 66$ & 60 & 53 & 16 & 37 & 21 & 8 & 0.09 \\
\hline Tölgyesi (15) & 2006 & Hungary & Caucasian & $144 / 174$ & 107 & 34 & 3 & 131 & 40 & 3 & 0.98 \\
\hline Sohn (16) & 2008 & Korea & Asian & $326 / 253$ & 109 & 146 & 71 & 97 & 107 & 49 & 0.05 \\
\hline
\end{tabular}

B, $-28 \mathrm{C} / \mathrm{G}$ polymorphism

\begin{tabular}{|c|c|c|c|c|c|c|c|c|c|c|c|}
\hline \multirow[b]{2}{*}{ First author (Refs.) } & \multirow[b]{2}{*}{ Year } & \multirow[b]{2}{*}{ Area } & \multirow[b]{2}{*}{ Ethnicity } & \multirow{2}{*}{$\begin{array}{l}\text { Cases/ } \\
\text { controls }\end{array}$} & \multicolumn{3}{|c|}{ Case genotypes } & \multicolumn{3}{|c|}{ Control genotypes } & \multirow{2}{*}{$\begin{array}{c}\text { HWE } \\
\text { test }\end{array}$} \\
\hline & & & & & $\mathrm{CC}$ & $\mathrm{CG}$ & GG & $\mathrm{CC}$ & $\mathrm{CG}$ & GG & \\
\hline Szalai (11) & 2001 & Hungary & Caucasian & $160 / 303$ & 144 & 16 & 0 & 284 & 19 & 0 & 0.57 \\
\hline Yao (12) & 2003 & China & Asian & $182 / 107$ & 134 & 39 & 9 & 83 & 23 & 1 & 0.67 \\
\hline Wang (17) & 2004 & China & Asian & $100 / 90$ & 65 & 31 & 4 & 72 & 17 & 1 & 1.00 \\
\hline Liu (13) & 2005 & China & Asian & $32 / 32$ & 25 & 6 & 1 & 29 & 3 & 0 & 0.78 \\
\hline Sohn (16) & 2008 & Korea & Asian & $326 / 253$ & 218 & 93 & 15 & 174 & 66 & 13 & 0.05 \\
\hline
\end{tabular}

HWE, Hardy-Weinberg equilibrium.

Selection criteria. The titles and abstracts of all citations identified by the literature search were reviewed. Selection criteria were then applied to all potentially relevant studies. The selection criteria for inclusion in the meta-analysis were: i) case-control studies conducted to evaluate the association between RANTES gene polymorphisms (-403G/A and $-28 \mathrm{C} / \mathrm{G}$ ) and pediatric asthma risk; ii) sufficient genotype data were presented to calculate the odds ratios (ORs) and 95\% confidence intervals (CIs); iii) the study should clearly describe pediatric asthma diagnoses and the sources of cases and controls. Studies were excluded when: i) they were non-case-control studies that evaluated the association between RANTES gene polymorphisms and pediatric asthma risk; ii) they were case reports, letters, reviews or editorial articles; iii) they were studies based on incomplete raw data and no usable data were reported; iv) they contained duplicate data.

Data extraction. The following characteristics were collected from each study: first author, year of publication, region of the first or corresponding author, ethnicity, number of cases and controls, number of genotypes and evidence of Hardy-Weinberg equilibrium (HWE; Table I). Ethnicities were classified as Asian or Caucasian. If original genotype frequency data were unavailable in the relevant articles, an email was sent to the corresponding author for additional data. For conflicting evaluations, an agreement was reached following a discussion.
Statistical analysis. A meta-analysis was performed using the STATA package version 12.0 (Stata Corporation, College Station, TX, USA). The OR corresponding to the 95\% CI was used to assess the intensity of the association between RANTES gene polymorphisms $(-403 \mathrm{G} / \mathrm{A}$ and $-28 \mathrm{C} / \mathrm{G})$ and pediatric asthma under a homozygote comparison (AA vs. aa), a heterozygote comparison (AA vs. Aa), a dominant model and a recessive mode between groups. In the current study, the dominant model was defined as Aa+aa vs. AA, where 'A' and 'a' are major and minor alleles, respectively, and the recessive model as aa vs. AA+Aa. The distribution of genotypes in the included studies was tested for HWE using the $\chi^{2}$ test. The effect of heterogeneity by the Q-test and $\mathrm{I}^{2}$ test was also quantified. $\mathrm{I}^{2}$ ranges between 0 and $100 \%$ and $\mathrm{I}^{2}$ values of 25,50 and $75 \%$ were defined as low, moderate and high estimates, respectively. When a significant $\mathrm{Q}$-test $(\mathrm{P}<0.10)$ or $\mathrm{I}^{2}>50 \%$ indicated heterogeneity across studies, the random-effects model was used for meta-analysis, otherwise the fixed-effects model was calculated. Sensitivity analysis was performed to assess the stability of the results by excluding the study by Sohn et al (16) with genotype distributions not in HWE. Begg's test was used to provide evidence of publication bias, shown as a funnel plot. $\mathrm{P}<0.05$ was considered to indicate a statistically significant result.

\section{Results}

Characteristics of studies. There were 287 studies relevant to the search words. Through screening the title and reading the 
Table II. Summary ORs and 95\% CIs of RANTES gene polymorphisms and pediatric asthma risk.

\begin{tabular}{|c|c|c|c|c|c|c|c|c|c|c|}
\hline \multirow[b]{2}{*}{ Subgroup } & \multirow[b]{2}{*}{ Genetic model } & \multicolumn{2}{|c|}{ Sample size } & \multirow[b]{2}{*}{ Type of model } & \multicolumn{2}{|c|}{ Heterogeneity } & \multicolumn{2}{|c|}{ Association } & \multicolumn{2}{|c|}{ Publication bias } \\
\hline & & Case & Control & & $\mathrm{I}^{2}(\%)$ & P-value & OR & $95 \% \mathrm{CI}$ & $\mathrm{z}$ & P-value \\
\hline \multicolumn{11}{|l|}{$-403 \mathrm{G} / \mathrm{A}$} \\
\hline \multirow[t]{4}{*}{ Overall } & AA vs. GG & 973 & 935 & Fixed & 0.0 & 0.98 & 1.34 & $0.95-1.89$ & 0.00 & 1.00 \\
\hline & AA vs. GA & & & Fixed & 0.0 & 0.75 & 1.18 & $0.84-1.66$ & 0.00 & 1.00 \\
\hline & Dominant & & & Fixed & 0.0 & 0.94 & 0.81 & $0.59-1.11$ & 0.00 & 1.00 \\
\hline & Recessive & & & Fixed & 3.6 & 0.39 & 1.06 & $0.87-1.29$ & 0.00 & 1.00 \\
\hline \multirow[t]{4}{*}{ Caucasian } & AA vs. GG & 304 & 477 & Fixed & 0.0 & 0.95 & 1.27 & $0.52-3.13$ & 0.00 & 1.00 \\
\hline & AA vs. GA & & & Fixed & 0.0 & 0.62 & 1.66 & $0.65-4.24$ & 0.00 & 1.00 \\
\hline & Dominant & & & Fixed & 0.0 & 0.86 & 0.73 & $0.30-1.80$ & 0.00 & 1.00 \\
\hline & Recessive & & & Fixed & 22.2 & 0.26 & 0.84 & $0.60-1.17$ & 0.00 & 1.00 \\
\hline \multirow[t]{4}{*}{ Asian } & AA vs. GG & 669 & 458 & Fixed & 0.0 & 0.87 & 1.35 & $0.93-1.96$ & 0.34 & 1.00 \\
\hline & AA vs. GA & & & Fixed & 0.0 & 0.61 & 1.12 & $0.78-1.62$ & 0.34 & 1.00 \\
\hline & Dominant & & & Fixed & 0.0 & 0.75 & 0.82 & $0.58-1.15$ & 0.34 & 1.00 \\
\hline & Recessive & & & Fixed & 0.0 & 0.81 & 1.21 & $0.95-1.54$ & 0.34 & 1.00 \\
\hline \multicolumn{11}{|l|}{$-28 \mathrm{C} / \mathrm{G}$} \\
\hline \multirow[t]{4}{*}{ Overall } & GG vs. CC & 800 & 785 & Fixed & 30.0 & 0.23 & 1.53 & $0.81-2.90$ & 0.24 & 1.00 \\
\hline & GG vs. CG & & & Random & 82.5 & 0.00 & 4.93 & $0.48-50.53$ & 0.24 & 1.00 \\
\hline & Dominant & & & Fixed & 26.4 & 0.25 & 0.69 & $0.37-1.29$ & 0.24 & 1.00 \\
\hline & Recessive & & & Fixed & 13.7 & 0.33 & 1.34 & $1.04-1.72$ & 0.24 & 1.00 \\
\hline \multirow[t]{4}{*}{ Asian } & GG vs. CC & 640 & 482 & Fixed & 30.0 & 0.23 & 1.53 & $0.81-2.90$ & 1.02 & 0.31 \\
\hline & GG vs. CG & & & Random & 82.5 & 0.00 & 4.93 & $0.48-5053$ & 1.02 & 0.31 \\
\hline & Dominant & & & Fixed & 26.4 & 0.25 & 0.69 & $0.37-1.29$ & 1.02 & 0.31 \\
\hline & Recessive & & & Fixed & 28.6 & 0.24 & 1.30 & $1.00-1.70$ & 1.02 & 0.31 \\
\hline
\end{tabular}

OR, odds ratio; CI, confidence interval; RANTES, regulated upon activation, normal T cells expressed and secreted.

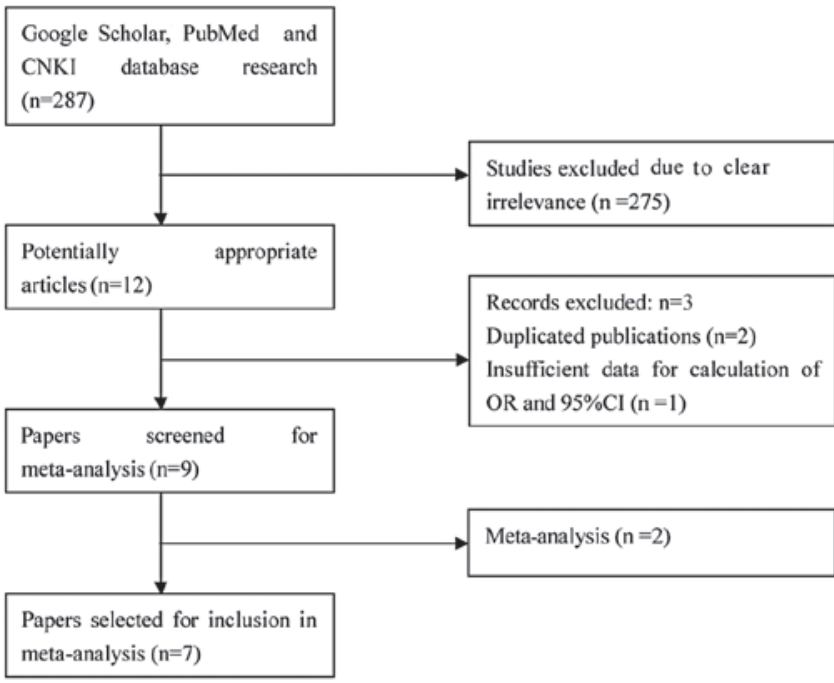

Figure 1. Flow diagram of study searching and selection process.

abstract and the entire article, 7 eligible articles were selected for this meta-analysis (Fig. 1). All the studies were case-control studies that evaluated the association between RANTES gene polymorphisms and pediatric asthma risk (11-17). For $-28 \mathrm{C} / \mathrm{G}$, the sample population in the Europe group was inadequate and ethnicity-specific meta-analysis was not conducted on Caucasians. The HWE test was performed on the genotype distribution of the controls in all included studies; all of them were in HWE except that in the study by Sohn et al (16). The main characteristics of the included studies are listed in Table I.

Results of meta-analysis. A summary of the meta-analysis findings of the association between RANTES gene polymorphisms $(-403 \mathrm{G} / \mathrm{A}$ and $-28 \mathrm{C} / \mathrm{G})$ and pediatric asthma risk is shown in Table II. Meta-analysis results showed that there was no association between the $-403 \mathrm{G} / \mathrm{A}$ polymorphism and the risk of pediatric asthma, the meta-analysis indicated that the $-28 \mathrm{C} / \mathrm{G}$ polymorphism was associated with an increased risk of pediatric asthma in the general population (recessive model: OR, 1.34; 95\% CI, 1.04-1.72). On the basis of the potential overestimation of the true effect of the polymorphism on the pediatric asthma risk, these studies were stratified according to ethnicity. In the stratified analysis, no significant associations were identified in Asian and European populations. Sensitivity analysis was performed to assess the stability of the results by excluding one study by Sohn et al (16) with genotype distributions not in HWE and the exclusion of any single study did not alter the significance of the final decision, suggesting that the outcomes were robust. The funnel plot and Begg's test were 


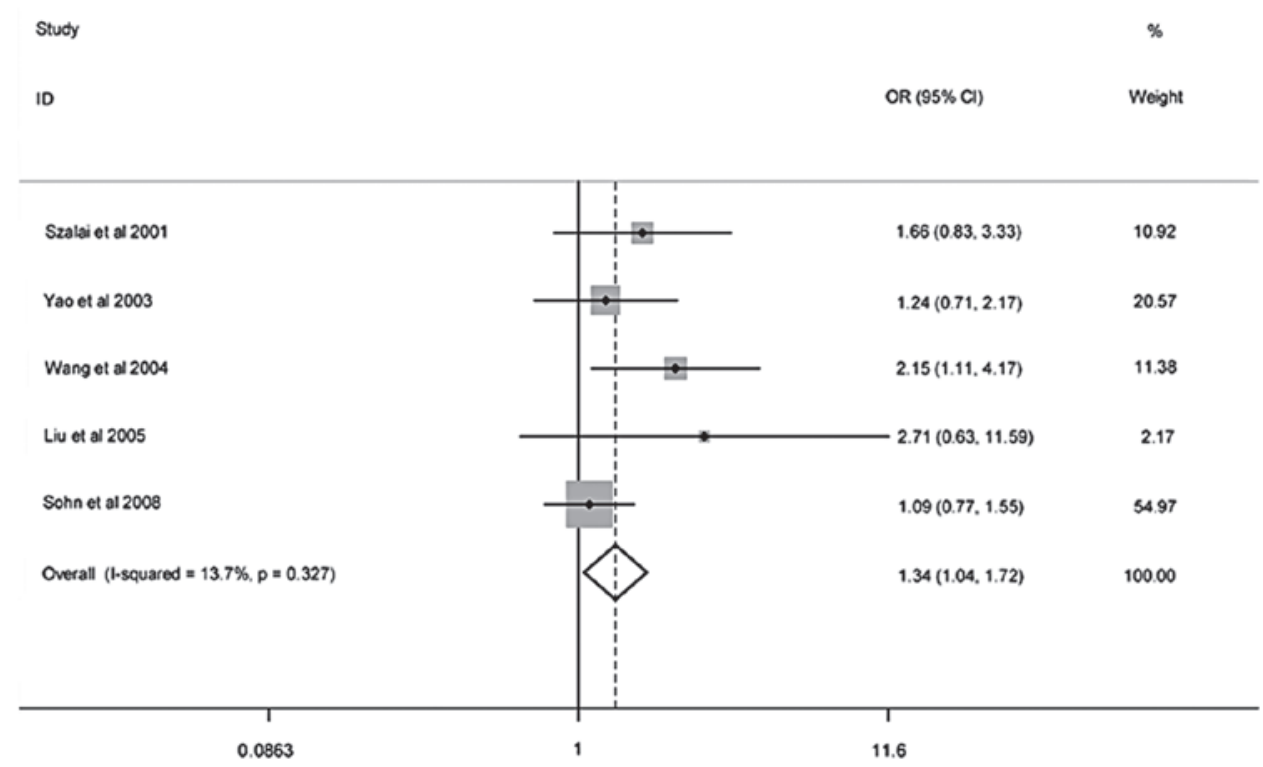

Figure 2. Meta-analysis of the correlation between the $-28 \mathrm{C} / \mathrm{G}$ polymorphism and pediatric asthma risk using a recessive model.

used to assess the publication bias. There was no evidence of publication bias visually from the funnel plot (Fig. 2, Table II). The difference was not significant in Begg's test (all P>0.05), suggesting that the publication bias was low in the present meta-analysis.

\section{Discussion}

Asthma is the most common chronic childhood disease (18). The pathogenesis of asthma is extremely complex and not fully understood, although the correlation of a variety of genetic loci and multiple environmental factors have been suggested as significant determinants of this disease $(19,20)$. A number of research studies have evaluated the association of RANTES gene polymorphisms (-403G/A and $-28 \mathrm{C} / \mathrm{G})$ and pediatric asthma risk, but the results are controversial, making it difficult to speculate the true correlation between gene polymorphisms and pediatric asthma. The studies included were conducted in various populations, sample sizes were relatively small and various criteria were used for the phenotype definition (21).

To the best of our knowledge, this is the first meta-analysis to consider RANTES gene polymorphisms and pediatric asthma. This meta-analysis quantitatively assessed the association between RANTES gene polymorphisms (-403G/A and $-28 \mathrm{C} / \mathrm{G}$ ) and susceptibility to pediatric asthma. Additonally, the results of our meta-analysis did not show any significant association between -403G/A polymorphism and pediatric asthma risk. As for $-28 \mathrm{C} / \mathrm{G}$, the meta-analysis indicated a significant association between $-28 \mathrm{C} / \mathrm{G}$ polymorphism and pediatric asthma susceptibility among the total population (recessive model: OR, 1.34; 95\% CI, 1.04-1.72). However, when the subgroup analyses were performed by ethnicity, no significant associations were identified in Asian and European populations. This result suggests that the $-28 \mathrm{C} / \mathrm{G}$ polymorphism may not be associated with pediatric asthma risk and the observed increase in the risk of pediatric asthma may be due to a bias of racial differences. Sensitivity analysis was performed to assess the stability of the results by excluding the study by Sohn et al (16) with genotype distributions that were not in HWE, suggesting that the results of the meta-analysis were reliable. No evidence revealed publication bias in this meta-analysis for the association between RANTES gene polymorphisms and susceptibility to pediatric asthma.

There were certain limitations to this meta-analysis. First, the linkage disequilibrium of $-403 \mathrm{G} / \mathrm{A}$ and $-28 \mathrm{C} / \mathrm{G}$ of the RANTES gene may synergistically increase the risk of asthma (22). There was insufficient individual information on genotypes of the RANTES -403G/A and -28C/G polymorphisms and combined analysis of linkage disequilibrium was therefore not performed. Consequently, more studies with larger sample sizes and providing more detailed information are required. Second, the effect of gene-gene and gene-environment interactions was not addressed in this meta-analysis. Third, the significance between study-heterogeneity was observed. Although the random-effect model was used to pool ORs, it may have affected the precision of results.

In conclusion, these results suggest that RANTES gene polymorphisms (-403G/A and $-28 \mathrm{C} / \mathrm{G})$ may not be involved with the susceptibility of pediatric asthma. Owing to the previously mentioned limitations, the findings should be verified by further research in the near future.

\section{References}

1. Zhang J, Paré PD and Sandford AJ: Recent advances in asthma genetics. Respir Res 9: 4, 2008.

2. Bloom B, Cohen RA and Freeman G: Summary Health Statistics for U.S. Children: National Health Interview Survey, 2009. Vital Health Stat 10: 1-82, 2010.

3. Schwerk N, Brinkmann F, Soudah B, et al: Wheeze in preschool age is associated with pulmonary bacterial infection and resolves after antibiotic therapy. PLoS One 6: e27913, 2011.

4. Covar RA, Strunk R, Zeiger RS, et al; Childhood Asthma Management Program Research Group: Predictors of remitting, periodic, and persistent childhood asthma. J Allergy Clin Immunol 125: 359-366, 2010.

5. Bisgaard H, Hermansen MN, Bønnelykke K, et al: Association of bacteria and viruses with wheezy episodes in young children: prospective birth cohort study. BMJ 341: c4978, 2010. 
6. Purcell S, Neale B, Todd-Brown K, Thomas L, Ferreira MA, Bender D, et al: PLINK: a tool set for whole-genome association and population-based linkage analyses. Am J Hum Genet 81: 559-575, 2007.

7. Litonjua AA, Carey VJ, Burge HA, Weiss ST and Gold DR: Parental history and the risk for childhood asthma. Does mother confer more risk than father? Am J Respir Crit Care Med 158: 176-181, 1998.

8. Lukacs NW, Strieter RM, Warmington K, Lincoln P, Censue SW and Kunkel SL: Differential recruitment of leukocyte populations and alteration of airway hyperreactivity by $\mathrm{C}-\mathrm{C}$ family chemokines in allergic airway inflammation. J Immunol 158: 4398-4404, 1997.

9. Nickel RG, Casolaro V, Wahn U, Beyer K, Barnes KC, Plunkett BS, et al: Atopic dermatitis is associated with a functional mutation in the promoter of the $\mathrm{C}-\mathrm{C}$ chemokine RANTES J Immunol 164: 1612-1616, 2000.

10. Liu H, Chao D, Nakayama EE, Taguchi H, Goto M, Xin X, et al: Polymorphism in RANTES chemokine promoter affects HIV-1 disease progression. Proc Natl Acad Sci USA96: 4581-4585, 1999.

11. Szalai C, Kozma GT, Nagy A, et al: Polymorphism in the gene regulatory region of MCP-1 is associated with asthma susceptibility and severity. J Allergy Clin Immunol 108: 375-381, 2001.

12. Yao TC, Kuo ML, See LC, et al: The RANTES promoter polymorphism: a genetic risk factor for near-fatal asthma in Chinese children. J Allergy Clin Immunol 111: 1285-1292, 2003.

13. Liu M, Li HL, Huang YK, et al: The SNPs of chemokine RANTES promoter in children with asthma. Zhong Guo You Sheng Yu Yi Chuan Za Zhi 13: 20-24, 2005 (In Chinese).
14. Leung TF, Tang NL, Lam CW, et al: RANTES G-401A polymorphism is associated with allergen sensitization and FEV1 in Chinese children. Respir Med 99: 216-219, 2005.

15. Tölgyesi G, Keszei M, Ungvari I, et al: Involvement of TNFalpha-308A promoter polymorphism in the development of asthma in children infected with Chlamydophila pneumoniae. Pediatr Res 60: 543-548, 2006.

16. Sohn MH, Kim SH, Kim KW, et al: RANTES gene promoter polymorphisms are associated with bronchial hyperresponsiveness in Korean children with asthma. Lung 186: 37-43, 2008.

17. Wang LJ, Li YR, Chen JH, et al: Polymorphism of regulated upon activation, normal $\mathrm{T}$ cell expressed and secreted promoter region-28 position in Chinese allergic asthmatic children. Zhonghua Jie He He Hu Xi Za Zhi 27: 394-397, 2004 (In Chinese).

18. Richards W: Hospitalization for children with status asthmaticus: A review. Pediatrics 84: 111-118, 1989.

19. Maddox L and Schwartz DA: The pathophysiology of asthma. Annu Rev Med 53: 477-498, 2002.

20. Sengler C, Lau S, Wahn U and Nickel R: Interactions between genes and environmental factors in asthma and atopy: new developments. Respir Res 3: 7, 2002.

21. Angles MR, Ocaña DB, Medellín BC and Tovilla-Zárate C: No association between the HTR1A gene and suicidal behavior: a meta-analysis. Rev Bras Psiquiatr 34: 38-42, 2012.

22. Hizawa N, Yamaguchi E, Konno S, et al: A functional polymorphism in the RANTES gene promoter is associated with the development of late-onset asthma. Am J Respir Crit Care Med 166: 686-690, 2002. 